\title{
CSF/serum quotient graphs for the evaluation of intrathecal $\mathbf{C}_{4}$ synthesis

\author{
Barbara Padilla-Docal, Alberto J Dorta-Contreras*, Raisa Bu-Coifiu-Fanego \\ and Alexis Rodriguez Rey
}

\begin{abstract}
Address: Central Laboratory of Cerebrospinal Fluid (LABCEL) Faculty of Medical Sciences "Dr Miguel Enriquez" Superior Institute of Medical Sciences of Havana AP 10049, 11000 CP Havana City, Cuba

Email: Barbara Padilla-Docal - barbara.padilla@infomed.sld.cu; Alberto J Dorta-Contreras* - adorta@infomed.sld.cu; Raisa Bu-CoifiuFanego - raisabu@infomed.sld.cu; Alexis Rodriguez Rey - alexisrodriguez@infomed.sld.cu

* Corresponding author
\end{abstract}

Published: 2 July 2009

Cerebrospinal Fluid Research 2009, 6:8 doi:10.1186/1743-8454-6-8
Received: 3 February 2009

Accepted: 2 July 2009

This article is available from: http://www.cerebrospinalfluidresearch.com/content/6/1/8

(c) 2009 Padilla-Docal et al; licensee BioMed Central Ltd.

This is an Open Access article distributed under the terms of the Creative Commons Attribution License (http://creativecommons.org/licenses/by/2.0), which permits unrestricted use, distribution, and reproduction in any medium, provided the original work is properly cited.

\begin{abstract}
Background: Cerebrospinal fluid (CSF)/serum quotient graphs have been used previously to determine local synthesis in brain of immunoglobulins and $C_{3}$ complement component. The aim of this study was to use the same technique to construct quotient graphs, or Reibergrams, for the beta globulin $\mathrm{C}_{4}$ and to evaluate the method for assessing intrathecal synthesis in neurological disease.

Methods: The constants in the previously-defined Reibergram for immunoglobulin IgA were used to calculate the CSF/serum quotient for $\mathrm{C}_{4}$. CSF and serum were analyzed for $\mathrm{C}_{4}$, IgA and albumin from a total of 12 patients with meningoencephalitis caused by encapsulated microorganisms and 10 subjects without infections or inflammatory neurological disease, some of which had dysfunction of the blood-CSF barrier,

Results: The formula and $\mathrm{C}_{4}$ Reibergram with the constants previously found for IgA, determined the intrathecal $\mathrm{C}_{4}$ synthesis in CSF. The intrathecal $\mathrm{C}_{4}$ fraction in $\mathrm{CSF}\left(\mathrm{C}_{4}\right.$ loc in $\left.\mathrm{mg} / \mathrm{l}\right)$ was compared to the $\mathrm{C}_{4}$-Index (fraction of CSF: serum for $\mathrm{C}_{4}$ /fraction of CSF: serum for albumin). There was a significant correlation between the two formulae. The CSF/Serum quotient graph was superior for detecting intrathecal synthesis of $\mathrm{C}_{4}$ under variable conditions of blood-CSF barrier permeability.

Conclusion: The $\mathrm{C}_{4}$ Reibergram can be used to quantify the intrathecal synthesis of this component of the complement system in different infectious diseases of the central nervous system and is especially useful for patients with blood-brain barrier dysfunction.
\end{abstract}

\section{Background}

Cerebrospinal fluid (CSF) analysis has great potential for the diagnosis of neurological diseases. Reibergrams or $\mathrm{CSF} /$ serum quotient graphs $[1,2]$ are diagrams that analyze in an integrated way both the function of the bloodCSF barrier and intrathecal protein synthesis, to aid in the diagnosis of central nervous system (CNS) diseases associated with specific patterns of immunoglobulin response. This diagram was first defined for the major classes of immunoglobulins $[2,3]$ empirically based on the results of thousands of profiles and was subsequently confirmed by application of Fick's law of diffusion in the 
theory of molecular diffusion/flow rate [4]. Fick's law states that the diffusion of a protein through a barrier depends on the diffusion coefficient of the molecule and on the concentration gradient between the compartments on either side of the barrier. The diffusion coefficient depends on the molecular size of the protein. Fick's second law shows how the local concentration gradient is nonlinearly modified by variations in the CSF flow rate. The theory of molecular diffusion/flow rate of CSF explains that the diffusion of proteins through the blood/ CSF barrier has a hyperbolic distribution and is able to explain the physiological and pathophysiological dynamics of proteins in the CNS. This has permitted its use for other immunoglobulins such as $\operatorname{IgG}_{3}[5]$, IgE [6] and more recently $\mathrm{C}_{3 \mathrm{c}}$ [7].

The complement system is one of the humoral mediators of immunity and inflammation; it is formed by more than thirty plasma and membrane proteins. Raised levels of $\mathrm{C}_{4}$, one of the components, may be found in the CSF in lupus meningoencephalitis $[8,9]$, in progressive supranuclear palsy [10] and other neurological diseases [11] such as autism [12], schizophrenia [13], cerebral parenchymal cysticercosis [14], meningoencephalitis [15] and brain tumors [16]. Cytokines associated with amyloid plaques in Alzheimer's disease stimulate human glial and neuronal cell cultures to secrete early complement proteins $[17,18]$. Some of these proteins are bound to immunoglobulins or to components of the cellular membrane [19], although they normally circulate in the form of proenzymes with a latent pro-enzyme activity.

$\mathrm{C}_{4}$ protein is a beta globulin with a sedimentation coefficient of 18.7, molecular weight $200 \mathrm{kDa}$ and a serum concentration of $430 \mu \mathrm{g} / \mathrm{mL}$. It is activated by the complement system and is a $\mathrm{C}_{2}$ receptor. $\mathrm{C} 4 \mathrm{a}$ acts as anaphylatoxin similar to $\mathrm{C}_{3 \mathrm{a}}$ but is weaker, while $\mathrm{C}_{4 \mathrm{~b}}$ acts as an opsonin promoting phagocytosis by binding to complement receptors. It is important to assess $\mathrm{C}_{4}$ intrathecal synthesis if the classical complement pathway has been activated in infectious and autoimmune neurological diseases. Combined with analysis of $\mathrm{C}_{3 \mathrm{c}}$ intrathecal synthesis $[20,21]$, this knowledge is needed to understand the pathophysiology of these disorders.

The aim of this paper was to construct quotient graphs (Reibergrams) for the beta globulin $\mathrm{C}_{4}$ and to determine the intrathecal synthesis of $\mathrm{C}_{4}$ in patients with bacterial meningoencephalitis. To do this we used IgA which has molecular characteristic similar to the $\mathrm{C}_{4}$ molecule and its previously-defined CSF/serum quotient graph, to create the formula and Reibergram for $\mathrm{C}_{4}$.

\section{Methods \\ Patients}

Twelve patients with meningoencephalitis caused by encapsulated microorganisms were studied: nine patients suffering from Streptococcus pneumoniae and three with Haemophilus influenzae (mean age of 32.5 years, range 3 to 46 years). A control group consisted of ten subjects without infections or inflammatory neurological disease and that did or did not have dysfunction of the blood-CSF barrier (mean age 17 years, range 9 months to 48 years), The research was approved by the Committee on Bioethics Research of the Faculty of Medical Sciences, Dr. Miguel Enriquez Superior Institute of Medical Sciences of Havana, Havana City, Cuba. All patients and persons whose samples were used as controls, and parents or tutors of the children gave their informed consent to carry out a diagnostic lumbar puncture.

\section{CSF and serum samples}

CSF samples were obtained by lumbar puncture and simultaneous blood samples were taken to obtain serum. Cells were removed from CSF by centrifugation and samples with blood contamination were eliminated. Control samples were from CSF and serum collections held in our laboratory from patients with suspicion of meningoencephalitis but were subsequently found to have febrile convulsions without biological agents or verified autoimmune causes. Aliquots of both patient and control samples were kept at $-70^{\circ} \mathrm{C}$ for up to 30 days after the puncture date before analysis.

\section{Analysis of CSF and serum}

$\mathrm{C}_{4}$, IgA and albumin were quantified by radial immunodiffusion with NOR PARTIGEN ${ }^{\circledR}$ and LC PARTIGEN $^{\odot}$ plates (Dade Behring, Marburg, Germany) for serum and CSF, respectively. Radial immunodiffusion detects the reaction of antigen and antibody by a precipitation reaction based on the principle that a quantitative relationship exists between the amount of antigen placed in a well cut in the agar-antibody plate and the resulting ring of precipitation. This end point method requires that the precipitation rings reach the maximal possible size, which often requires $48-72 \mathrm{~h}$ of diffusion. A standard curve was experimentally determined with known standards and used for the determination of protein concentration corresponding to any diameter size.

\section{$C_{4}$ Reibergram and index}

The CSF/Serum quotient graph or Reibergram for $\mathrm{C}_{4}$ was created taking into consideration the molecular characteristics of this protein. In addition, the $\mathrm{C}_{4}$-Index was calculated using the following formula [22]:

$\mathrm{C}_{4}-$ Index $=\left(\mathrm{C}_{4} \mathrm{CSF} / \mathrm{C}_{4}\right.$ serum $) /($ Albumin $\mathrm{CSF} /$ Albumin serum $)=\mathrm{Q} \mathrm{C}_{4} / \mathrm{QAlb}$ 
As a cut off for discrimination between a normal and pathological $\mathrm{C}_{4}$-Index, we used $\mathrm{C}_{4}$-Index $=0.46$

Among proteins found in CSF and serum, $\mathrm{C}_{4}$ is most similar to IgA in terms of molecular characteristics (Table 1). The constants used for the creation of the formula for intrathecal $\mathrm{C}_{4}$ detection were those for IgA [3] which are likely to be similar to $\mathrm{C}_{4}$ according to Fick's law of diffusion. Hence the Reiber's quotient for $\mathrm{C}_{4}$ was calculated using the following formula:

$$
Q C_{4}(\lim )=\frac{a}{b} \sqrt{Q_{A l b}^{2}+b^{2}}-c
$$

Where $\mathrm{Q} \mathrm{C}_{4}$ (lim) is the upper discrimination line of the reference range, $\mathrm{Q} \mathrm{C}_{4}=\mathrm{C}_{4}(\mathrm{CSF}) / \mathrm{C}_{4}$ (Serum), $\mathrm{a}=$ intercept hyperbole value on the $\mathrm{y}$ axis, $\mathrm{b}=\mathrm{x}$ value to asymptotic hyperbole line, $\mathrm{c}=$ constant and $\mathrm{a} / \mathrm{b}=$ hyperbole slope. The following values previously obtained for IgA were used: $\mathrm{a} / \mathrm{b}=0.77, \mathrm{~b}^{2}=23 \times 10^{-6}, \mathrm{c}=3.1 \times 10^{-3}$.

Thus the formula for the amount of locally-synthesized $\mathrm{C}_{4}$ in the $\mathrm{CSF}$ or $\mathrm{C}_{4}$ (loc) is:

$$
\mathrm{C}_{4}(\mathrm{loc})=\mathrm{Q} \mathrm{C}_{4}-\left(0.77 \sqrt{\mathrm{QAlb}^{2}+23 \times 10^{-6}}+3.1 \times 10^{-3}\right) \times \mathrm{C}_{4} \text { serum }
$$

The program MEDCALC version 6.0 was used to perform the statistical comparison.

\section{Results}

The $\mathrm{Q} \mathrm{C}_{4}$ quotient graph for the patients and controls under study with a range of values of $Q$ albumin (QAlb) is shown in figure 1 . The $\mathrm{Q} \mathrm{C}_{4}$ values for all twelve patients with meningoencephalitis are above the lower thin hyperbolic line. For nine of these twelve patients $\mathrm{Q} \mathrm{C}_{4}$ was located above the upper solid line showing that these patients synthesized $\mathrm{C}_{4}$ intrathecally. The $\mathrm{Q} \mathrm{C}_{4}$ for all control patients is in the area between the thick hyperbolic line and the lower thin line, indicating that there is no CNS synthesis of this component. Also included is the QIgA of the patients with inflammatory meningoencephalitis and only five of these are in the region that indicates intrathecal synthesis. Another two patients had no detectable IgA in CSF. Hence the pattern of intrathecal synthesis of IgA is not the same as for $\mathrm{C}_{4}$, suggesting that IgA has a different role in the immune response, despite

Table I: Molecular characteristics of immunoglobulins and complement proteins

\begin{tabular}{llllll}
\hline & $\lg _{1}$ & $\lg \mathrm{A}$ & $\lg M$ & $\mathrm{C}_{3 c}$ & $\mathrm{C}_{4}$ \\
\hline Molecular Mass (kDa) & 150 & 160 & 900 & 145 & 200 \\
\hline Hydrodynamic radius (nm) & 52 & 58 & 270 & 54 & 65
\end{tabular}

the similar molecular flux from blood to CSF according to the molecular size. Mean values, range and coefficient of variation for $\mathrm{C}_{4}$ and IgA in serum and CSF are shown in Table 2.

Hitherto, the formula used to quantify the intrathecal synthesis of $\mathrm{C}_{4}$ complement has been the $\mathrm{C}_{4}$-Index $[22,23]$. In this study, the results obtained from the CSF/Serum quotient formula were compared to $\mathrm{C}_{4}$-Index values. Using $\mathrm{C}_{4}$-Index, among the non-inflammatory controls, there were 2 false positives, although intrathecal complement synthesis should not occur in such cases. With $\mathrm{C}_{4}$-Index > 0.46 we find in $10 / 12$ case of meningoencephalitis a pathological increase, i.e. an intrathecal synthesis (Table 3 ).

There was a positive correlation between the $\mathrm{C}_{4}$-Index and the CSF/Serum quotient graph for $\mathrm{C}_{4}, \mathrm{r}=0.7287$ and range $0.4432-0.8800$, for a confidence interval of $95 \%$, $p=0.0001$. The general sensitivity of $\mathrm{C}_{4}$-Index, i.e. the probability that this result will be positive when the inflammatory process is present, was only $66 \%$ of true positive rate. The $\mathrm{C}_{4}$-Index general specificity was $85 \%$, meaning that the probability that the $\mathrm{C}_{4}$-Index will be negative when the inflammatory process is not present was $85 \%$ of true negative. The positive predictive value or the probability that the inflammatory process is present when the index is positive was $75 \%$ and the negative predictive value or the probability that the inflammatory process is not present when the index is negative was $80 \%$. Hence the $\mathrm{C}_{4}$ quotient method (Reibergram) was found to be superior in sensitivity, specificity and predictive values.

\section{Discussion}

The complement system consists of more than thirty proteins and has three types of activation pathways: classical, lectin and alternative pathways. The complement system not only has a role in innate immunity but also works as an antibody-dependent effector to eliminate pathogens. In serum, normal or decreased levels of $\mathrm{C}_{3}$ and $\mathrm{C}_{4}$ are associated with specific immune-mediated diseases. In patients with immune-mediated diseases in the CNS, it is essential to measure complement activation in CSF and the intrathecal synthesis of complement proteins.

The immune response within the CNS has specific characteristics associated with a reduced immunological environment, being a unique and special compartment without much peripheral regulation. The CNS humoral immune response is different from the immune response observed in blood, mainly because there is no switch from the IgM class response to IgG or IgA class response in the CSF in the course of inflammatory neurological disease. The pattern of intrathecal $\mathrm{IgG} / \mathrm{IgA} / \mathrm{IgM}$ synthesis remains fairly constant and depends on the cause, pathophysiology and localization of the disease process $[3,4]$. In addi- 
Table 2: Mean value, range and coefficient of variation (CV) in CSF and serum for $\mathrm{C}_{4}$ and $\lg A$

\begin{tabular}{|c|c|c|c|}
\hline & & Meningoencephalitis & Controls \\
\hline Size (n) & & 12 & 10 \\
\hline \multirow[t]{3}{*}{$\mathrm{CSF} \mathrm{C}_{4}(\mathrm{mg} / \mathrm{L})$} & Mean & 12.07 & 2.43 \\
\hline & Range & $0.17-114$ & $0.17-12$ \\
\hline & $\mathrm{CV}$ & 2.67 & 1.60 \\
\hline \multirow[t]{3}{*}{ Serum $C_{4}(g / L)$} & Mean & 1.12 & 1.08 \\
\hline & Range & $0.19-5.6$ & $0.37-5.6$ \\
\hline & $\mathrm{CV}$ & 0.71 & 1.56 \\
\hline \multirow[t]{3}{*}{$\mathrm{QC}_{4} \times 10^{3}$} & Mean & 7.35 & 1.49 \\
\hline & Range & $1.1-39.4$ & $0.38-10.8$ \\
\hline & $\mathrm{CV}$ & 1.45 & 1.79 \\
\hline \multirow[t]{3}{*}{$\mathrm{Q} \mathrm{Alb} \times 10^{3}$} & Mean & 5.91 & 5.36 \\
\hline & Range & $0.3-17.1$ & $0.3-27.41$ \\
\hline & $\mathrm{CV}$ & 0.79 & 0.99 \\
\hline \multirow[t]{3}{*}{$\mathrm{C}_{4}$-Index } & Mean & 1.91 & 0.74 \\
\hline & Range & $0.3-5.05$ & $0.02-3.66$ \\
\hline & $\mathrm{CV}$ & 0.96 & 1.49 \\
\hline \multirow[t]{3}{*}{ CSF IgA (mg/L) } & Mean & 1.09 & 1.28 \\
\hline & Range & $0.17-4.62$ & $0.32-5.6$ \\
\hline & $\mathrm{CV}$ & 1.17 & 1.37 \\
\hline \multirow[t]{3}{*}{ Serum IgA $(g / L)$} & Mean & 1.12 & 0.67 \\
\hline & Range & $0.32-5.6$ & $0.17-1.7$ \\
\hline & $\mathrm{CV}$ & 1.38 & 0.90 \\
\hline \multirow[t]{3}{*}{$\mathrm{Q} \lg \mathrm{A} \times 10^{3}$} & Mean & 1.76 & 0.92 \\
\hline & Range & $0.16-10.62$ & $0.16-3.5$ \\
\hline & $\mathrm{CV}$ & 1.05 & 1.34 \\
\hline
\end{tabular}

Notes:

$\mathrm{Q}=$ quotient $(\mathrm{CSF} / \mathrm{Serum})$

Alb = Albumin

$\mathrm{C}_{4}$-Index $=\left(\mathrm{C}_{4} \mathrm{CSF} / \mathrm{C}_{4}\right.$ serum $) /($ Albumin CSF/Albumin serum $)$

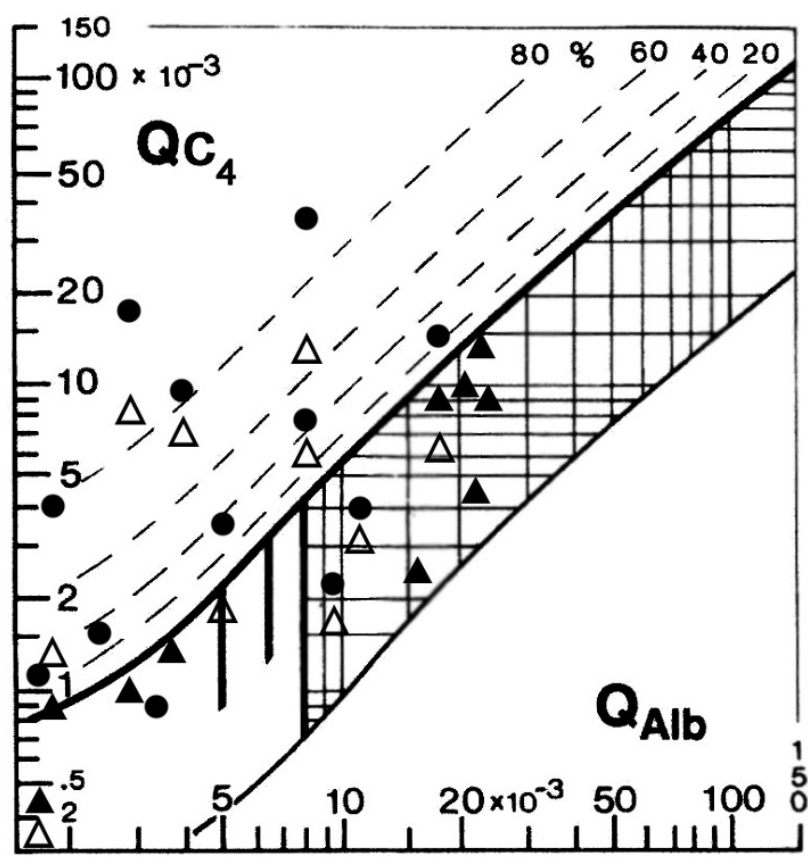

Figure I

CSF/serum quotient diagram for $\mathrm{C}_{4}$ (Reibergram). The upper hyperbolic curve (thick line) represents the discrimination line between brain-derived and blood-derived protein. Values above this upper line represent intrathecal $\mathrm{C}_{4}$ synthesis. The dashed hyperbolic lines indicate the extent of intrathecal synthesis as intrathecal fractions with $20,40,60$, and $80 \%$ of the measured total immunoglobulin concentration in CSF, with reference to the discrimination line as $0 \%$ intrathecal synthesis. The limit of the reference range for QAlbumin between normal and increased CSF protein concentrations due to blood-CSF barrier dysfunction is indicated by the age-dependent vertical lines at Q Albumin $5.5 \times 10-3$ (up to I5 years), at QAlbumin $6.5 \times 10-3$ (up to 40 years), and at Q Albumin $8 \times 10-3$ (up to 60 years). Nine of the patients with neurological infectious meningoencephalitis (Black circle) had values above the upper solid line which indicate intrathecal synthesis of $\mathrm{C}_{4}$. Ten controls (Black triangle) without infectious neurological disorders had values in the normal range, indicating no intrathecal $\mathrm{C}_{4}$ synthesis. Also plotted are QIgA (White triangle) from 10 patients suffering from meningoencephalitis and five of these had IgA intrathecal synthesis. Two patients had no detectable IgA in CSF. 
Table 3: Comparison of the results for intrathecal fraction of $C_{4}$ in CSF calculated as $C_{4} l o c(m g / l)$ and as the $C_{4}$-Index in patients with inflammatory disease and non-inflammatory controls.

\begin{tabular}{llccc}
\hline & & Intrathecal $C_{4}$ fraction & $C_{4}$-Index & $>0.46$ \\
\hline Meningoencephalitis & $C_{4}$ loc $>0$ & $C_{4}$ loc $<0$ & $10 / 12$ & $2 / 12$ \\
\hline Non inflammatory controls & $9 / 12$ & $3 / 12$ & $2 / 10 *$ & $8 / 10$ \\
\hline
\end{tabular}

The discrimination cut off for the $C_{4}$-Index $=0.46$.

$*$ Two false positives

tion, it is known that there is a long-lasting but slow decay of intrathecal antibody synthesis, sometimes detectable up to 20 years after sufficient treatment (e.g. in neurosyphilis, neuroborreliosis or HSV-encephalitis). In CSF, there are polyclonal and polyspecific immune responses in diseases like multiple sclerosis $[20,24]$. Recent studies have demonstrated that the intrathecal synthesis of $\mathrm{C}_{3 \mathrm{c}}$ is associated with infectious [14] and autoimmune disease [15].

Studies carried out on the passage of different blood proteins into the CSF have established different models that tried to explain their differential diffusion into the cerebral compartment. The theory of protein flux/CSF flow $[4,24]$ suggests that there is no loss of selectivity during dysfunction of the blood-CSF barrier, and that the only variable determining the speed of passage of a blood protein into CSF is the coefficient of molecular diffusion which is inversely proportional to the molecular size of the protein. The protein concentrations in CSF depend on blood concentration, blood-CSF barrier function and intrathecal synthesis [25]. In order to know if a protein in CSF is brain-derived it should have at least one of the following characteristics: a higher CSF concentration than in serum, the blood-derived fraction in CSF significantly lower than brain-derived fraction, or if the coefficient of variation $(\mathrm{CV})$ of the serum concentrations is larger than $\mathrm{CV}$ in CSF. In our experiment, the $\mathrm{C}_{4}$ concentration in blood was larger than in CSF in controls and in patients with meningoencephalitis. In the patient group, the CV in CSF was larger than in serum but in the control group, the $\mathrm{CV}$ was not larger in CSF than in blood. This suggests that although $\mathrm{C}_{4}$ is a blood-derived protein, during the inflammation process there was an increased amount produced in brain. This study showed that $75 \%$ of patients with meningoencephalitis had intrathecal $\mathrm{C}_{4}$ synthesis with or without dysfunction of the blood-CSF barrier as indicated by its QAlb value which varies according to age. In addition, the control group with variable QAlb values was in the normal range, indicating no intrathecal synthesis, which is consistent with the absence of cerebral inflam- mation in this group [26]. Also noteworthy is that none of the evaluated cases was placed below the lower hyperbolic curve, which is an area with no biological explanation. In medical practice, a technical error in protein quantification is suspected when a case falls in this area, so this is a quality control for the method.

Using the previously-used $\mathrm{C}_{4}$-Index to study intrathecal $\mathrm{C}_{4}$ synthesis has disadvantages over the quotient method. The index is a linear formula whereas the distribution of proteins from blood to cerebral compartments follows a hyperbolic curve [1], thus the $\mathrm{C}_{4}$-Index may produce false results [25]. In addition, indexes can not be applied when there is a dysfunction of the blood-CSF barrier, which greatly limits its application in inflammatory diseases that usually involve barrier dysfunction. There is also a practical problem; the values of the index vary with the volume of extracted CSF since there is a rostro-caudal concentration gradient of proteins passing into CSF, and the first and the following volumes collected have different concentrations [27]. However, it has been demonstrated that since the Reibergram works with protein quotients normalized to quotient (CSF/serum) these are not affected by the extracted CSF volume $[1,25,27]$.

Despite these limitations, the results of the $\mathrm{C}_{4}$ Reibergram were compared to those of the index since there is no other known gold standard. There was a positive significant statistical correlation between both methods. Nevertheless, these results demonstrated the superior diagnostic value of Reibergram.

\section{Conclusion}

Under all conditions of the blood-CSF barrier, the CSF/ Serum quotient graph can identify the occurrence of intrathecal $\mathrm{C}_{4}$ synthesis. It can quantify the $\mathrm{C}_{4}$ fraction which is locally produced in the CNS and differentiate from $\mathrm{C}_{4}$ that may have entered the CSF from blood. On the other hand, the $\mathrm{C}_{4}$-Index should not be used in patients with low QAlb and in particular with high QAlb, i.e. with blood-CSF barrier dysfunction. 


\section{Competing interests}

The authors declare that they have no competing interests.

\section{Authors' contributions}

BPD and AJDC designed and coordinated the study and drafted the manuscript. RBCF participated in its design and reviewed the clinical profiles of patients. ARR helped with protein analysis and in drafting the manuscript. All authors read and approved the final version of the manuscript.

\section{Acknowledgements}

The authors would like to thank Manuel Rodriguez for technical assistance.

\section{References}

I. Reiber H: Flow rate of cerebrospinal fluid (CSF): a concept common to normal blood CSF barrier function and to dysfunction in neurological diseases. J Neurol Sci I994, I 22: I89-203.

2. Reiber $\mathrm{H}$ : The hyperbolic function: a mathematical solution of the protein flux/CSF flow model for blood CSF barrier function. J Neurol Sci 1994, I 26:243-245.

3. Dorta Contreras A): Reibergrama: elemento esencial en el análisis inmunológico de líquido cefalorraquídeo. Rev Neurol 1999, 28:996-998.

4. Dorta Contreras AJ, Reiber H: Teoría de la difusión molecular flujo del líquido cefalorraquídeo. Rev Neurol 2004, 39:564-69.

5. Dorta Contreras AJ: Nuevo Reibergrama para la evaluación de la síntesis intratecal de IgG3. Rev Neurol 200I, 33:694-696.

6. Dorta Contreras AJ: Reibergrama para la evaluación de la síntesis intratecal de IgE. Rev Neurol 2004, 39:794-795.

7. Dorta Contreras AJ, Noris Garcia E, Padilla Docal B, Rodriguez Rey A, Bu-Coifiu-Fanego R, Magraner Tarrau ME, Marti Brenes M: Reibergrama para la evaluación de la síntesis intratecal de C3c. Arq Neuropsiquiatr 2006, 64:585-588.

8. Hazouard E, Legras A, Diot E, Ferrandière $M$, Corcia $P$, Giniès G: Liquide céphalo-rachidien complément et d'anticorps antinucléaires dans le lupus méningo-encéphalite. Rev Neurol (Paris) 1998, I 54:549-550.

9. Jongen PJ, Boerbooms AM, Lamers KJ, Raes BC, Vierwinden G: Dif fuse CNS involvement in systemic lupus erythematosus: intrathecal synthesis of the 4 th component of complement. Neurology 1990, 40:1593-1596.

10. Yamada T, Moroo I, Koguchi Y, Asahina M, Hirayama K: Increased concentration of $\mathbf{C 4 d}$ complement protein in the cerebrospinal fluids in progressive supranuclear palsy. Acta Neurol Scand 1994, 89:42-46.

II. Trbojeviæ-Cepe M, Brinar V, Pauro M, Vogrinc Z, Stambuk N: Cerebrospinal fluid complement activation in neurological diseases. J Neurol Sci 1998, I 54:173-181.

12. Ashwood $P$, Wills $S$, Water J Van de: The immune response in autism: a new frontier for autism research. J Leukoc Biol 2006, 80:I-I5.

13. Mayilyan KR, Weinberger DR, Sim RB: The complement system in schizophrenia. Drug News Perspect 2008, $21: 200-210$.

14. Estanol B, Juarez H, Irigoyen M, del C, Gonzalez Barranco D, Corona $\mathrm{T}$ : Humoral immune response in patients with cerebral parenchymal cysticercosis treated with praziquantel. J Neurol Neurosurg Psychiatry 1989, 52:254-257.

15. Brandtzaeg $P$, Høgasen $K$, Kierulf $P$, Mollnes TE: The excessive complement activation in fulminant meningococcal septicemia is predominantly caused by alternative pathway activation. J Infect Dis 1996, I 73:647-655.

16. Fishelson Z, Donin N, Zell S, Schultz S, Kirschfink M: Obstacles to cancer immunotherapy: expression of membrane complement regulatory proteins (mCRPs) in tumors. Mol Immunol 2003, 40:109-123.

17. Veerhuis R, Janssen I, De Groot CJ, Van Muiswinkel FL, Hack CE, Eikelenboom P: Cytokines associated with amyloid plaques in Alzheimer's disease brain stimulate human glial and neuronal cell cultures to secrete early complement proteins, but not Cl-inhibitor. Exp Neurol 1999, 160:289-299.
18. Bergamaschini L, Canziani S, Bottasso B, Cugno M, Braidotti P, Agostoni A: Alzheimer's beta-amyloid peptides can activate the early components of complement classical pathway in a Clq-independent manner. Clin Exp Immunol 1999, I I 5:526-533.

19. Carroll $\mathrm{M}$ : The complement system in regulation of adaptive immunity. Nat Immunol 2004, 5:98I-986.

20. Padilla-Docal B, Dorta-Contreras AJ, Bu-Coifiu-Fanego R: Activación y biosíntesis intratecal de $\mathrm{C} 3 \mathrm{c}$ en niños con meningoencefalitis eosinofílica por Angiostrongylus cantonensis . Rev Neurol 2009, 48:632-5.

21. Padilla-Docal B, Dorta-Contreras AJ, Fundora Hernández H, NorisGarcía E, Bu Coifiu-Fanego R, González-Hernández M, Rodríguez-Rey $A: \mathbf{C 3 c}$ intrathecal síntesis evaluation in patients with multiple sclerosis. Arq Neuropsiquiatr 2007, 65:800-802.

22. Fryden A, Forsberg $P$, Link H: Synthesis of the complement factors C3 and C4 within the central nervous system over the course of aseptic meningitis. Acta neurol Scand 1983, 68: I57-I63.

23. Dujardin BC, Roijers AF, Dreidijk PC, Out TA: The determination of the complement component $\mathrm{Clq}, \mathrm{C4}$, and $\mathrm{C} 3$ in serum and cerebrospinal fluid by radioimmunoassay. J Immunol Methods. 1985, 80(2):227-237.

24. Reiber H: Proteins in cerebrospinal fluid and blood: Barriers, CSF flow rate and source-related dynamics. Restor Neurol Neurosci 2003, $21: 79-96$

25. Reiber H, Peter JB: Cerebrospinal fluid analysis - diseaserelated data patterns and evaluation programs. I Neurol Sci 200I, I84:101-122

26. Reiber H, Albaum W: Statistical evaluation of intrathecal protein synthesis in CSF/serum quotient diagrams. Acta Neuropsychiatrica 2008, 20:48-49.

27. Wurster U: Protein gradient in the cerebrospinal fluid and the calculation of intracerebral IgG synthesis. J Neuroimmunol 1988, 20:233-235.

Publish with Bio Med Central and every scientist can read your work free of charge

"BioMed Central will be the most significant development for disseminating the results of biomedical research in our lifetime. "

Sir Paul Nurse, Cancer Research UK

Your research papers will be:

- available free of charge to the entire biomedical community

- peer reviewed and published immediately upon acceptance

- cited in PubMed and archived on PubMed Central

- yours - you keep the copyright 